\title{
CUGC for congenital primary aphakia
}

\author{
Hajrah Sarkar $^{1} \cdot$ William Moore $^{2} \cdot$ Bart P Leroy $^{3,4} \cdot$ Mariya Moosajee $^{1,2,5}$
}

Received: 16 June 2017 / Revised: 14 February 2018 / Accepted: 26 April 2018 / Published online: 16 May 2018

(c) European Society of Human Genetics 2018

\section{Name of the Disease (Synonyms)}

Congenital Primary Aphakia; CPA (Anterior Segment Dysgenesis 2; ASGD2).

\section{OMIM\# of the Disease}

610256.

\section{Name of the Analysed Genes or DNA/ Chromosome Segments}

FOXE3.

\section{OMIM\# of the Gene(s)}

601094.

Review of the analytical and clinical $\bigotimes$ diagnostic, validity as well as of the clinical utility $\triangle$ predictive and of DNA-based testing for mutations in the FOXE3 gene(s) in $\triangle$ prenatal settings and for

$\bigotimes$ risk assessment in relatives.

Mariya Moosajee

m.moosajee@ucl.ac.uk

1 UCL Institute of Ophthalmology, London, UK

2 Great Ormond Street Hospital for Children, London, UK

3 Ghent University Hospital \& Ghent University, Ghent, Belgium

4 The Children's Hospital of Philadelphia, Philadelphia, USA

5 Moorfields Eye Hospital NHS Foundation Trust, London, UK

\section{Disease characteristics}

\subsection{Name of the disease (Synonyms)}

Congenital Primary Aphakia; CPAK (Anterior Segment Dysgenesis 2; ASGD2).

\subsection{OMIM\# of the disease}

610256.

\subsection{Name of the analysed genes or DNA/ chromosome segments}

FOXE3.

\subsection{OMIM\# of the gene(s)}

601094.

\subsection{Mutational spectrum}

Congenital primary aphakia (CPAK) is characterised by the absence of the lens arising from failure of lens induction from the surface ectoderm and aborted lens development [1]. It is caused by variants in the FOXE3 gene, located on chromosome 1p33 and consists of a single exon $1981 \mathrm{bp}$ long (NCBI reference sequence NM_012186.2). FOXE3 encodes the 319 amino acid FOXE3 protein, a forkheadrelated transcription factor involved in lens formation. Most cases are autosomal recessive and $c .720 C>A$ p.(Cys240Ter) is the most common variant associated with CPAK [2-5]. There has been one report of a dominant pedigree with an affected family member with a right primary aphakia, sclerocornea, optic disc coloboma and microphthalmia, and left Peters anomaly with congenital cataract and mild microphthalmia resulting from a non-stop variant $c .958 T>C$ p.(Ter320ArgextTer72) [6].

It is important to note that both dominant and recessive variants in FOXE3 are associated with a variable mixed 
phenotype of developmental eye disorders including anterior segment dysgenesis, microphthalmia, Peters anomaly, sclerocornea, early onset cataract, glaucoma and ocular coloboma [4-7].

\subsection{Analytical methods}

Bi-directional fluorescent Sanger sequencing of coding and intron-exon boundaries of FOXE3 is the mainstay analytical method as an initial analysis. However, FOXE3 screening is being included on next-generation sequencing (NGS) exome gene panels in some laboratories.

\subsection{Analytical validation}

Parallel bi-directional fluorescent Sanger sequencing of known controls is required to validate procedures. Diagnostic testing must be carried out within a laboratory environment working to standards compliant with the ISO 15189.

\subsection{Estimated frequency of the disease}

(Incidence at birth ("birth prevalence") or population prevalence. If known to be variable between ethnic groups, please report):

CPAK is rare and the prevalence is unknown. Of the 9 families reported, 8 are consanguineous and 7 are of Pakistani origin, suggesting a higher incidence in this ethnic group (https://databases.lovd.nl/shared/diseases/02923).

\subsection{Diagnostic setting}

\begin{tabular}{lcc}
\hline & Yes & No \\
\hline A. (Differential) diagnostics & $\bigotimes$ & $\square$ \\
B. Predictive Testing & $\bigotimes$ & $\square$ \\
C. Risk assessment in Relatives & $\bigotimes$ & $\square$ \\
D. Prenatal & $\square$ & $\square$ \\
\hline
\end{tabular}

Comment: Not applicable

\section{Test characteristics}

\subsection{Analytical sensitivity (proportion of positive tests if the genotype is present)}

The analytical sensitivity of bi-directional Sanger sequencing is estimated to be $>98 \%$ for the detection of nucleotide base changes, small deletions and insertions in the regions analysed.

\subsection{Analytical specificity (proportion of negative tests if the genotype is not present)}

The analytical specificity of bi-directional Sanger sequencing is $>98 \%$ given current testing methodologies, based on false positives that may arise due to misinterpretation of rare polymorphic variants that rarely occur in Sanger sequencing.

\subsection{Clinical sensitivity}

(proportion of positive tests if the disease is present) The clinical sensitivity can be dependent on variable factors such as age or family history. In such cases a general statement should be given, even if a quantification can only be made case by case.

CPAK is a congenital eye defect presenting at birth with no lens formation and variably associated anterior segment dysgenesis. The clinical sensitivity is $>98 \%$.

\subsection{Clinical specificity}

(proportion of negative tests if the disease is not present) The clinical specificity can be dependent on variable factors such as age or family history. In such cases a general statement should be given, even if a quantification can only be made case by case.

A positive test in a patient without signs of this condition is extremely unlikely, and hence the clinical specificity will be high, nearing $100 \%$.

\subsection{Positive clinical predictive value}

(life time risk to develop the disease if the test is positive)

Estimated $>99 \%$ for FOXE3 variants, as CPAK presents in infancy.

\subsection{Negative clinical predictive value}

(Probability not to develop the disease if the test is negative). Assume an increased risk based on family history for a non-affected person. Allelic and locus heterogeneity may need to be considered.

Index case in that family had been tested:

Nearly $100 \%$ if no CPAK.

Index case in that family had not been tested:

Nearly $100 \%$ if no CPAK. 


\section{Clinical utility}

\section{1 (Differential) diagnostics: the tested person is clinically affected}

(To be answered if in 1.9 " $\mathrm{A}$ " was marked)

\subsubsection{Can a diagnosis be made other than through a genetic test?}

\begin{tabular}{ll}
\hline No. & $\square$ (continue with 3.1.4) \\
Yes, & $\bigotimes$ \\
& Clinically \\
& Imaging \\
& Endoscopy \\
& Biochemistry \\
& Electrophysiology \\
& Other (please describe): \\
\hline
\end{tabular}

\subsubsection{Describe the burden of alternative diagnostic methods to the patient}

If CPAK is suspected, a clinical diagnosis can be made based on clinical examination and confirmed with ultrasound. Anterior segment ultrasound biomicroscopy may aid detection of co-existent anterior segment dysgenesis.

Due to the association of CPAK and the rubella virus, a TORCH complex evaluation is also recommended [8].

\subsubsection{How is the cost effectiveness of alternative diagnostic methods to be judged?}

Clinical examination provides a cost effective diagnosis.

3.1.4 Will disease management be influenced by the result of a genetic test?

No.

Yes. $\square$

Therapy (please describe)

Prognosis (please CPAK is often associated with describe) other ocular anomalies, including microphthalmia, anterior segment dysgenesis, and glaucoma. Early
Table (continued)

\begin{tabular}{|c|c|}
\hline & $\begin{array}{l}\text { diagnosis will enable prompt sup- } \\
\text { portive treatment. }\end{array}$ \\
\hline $\begin{array}{l}\text { Management } \\
\text { (please describe) }\end{array}$ & $\begin{array}{l}\text { CPAK should be managed by } \\
\text { specialists with expertise in the } \\
\text { condition. Supportive measures for } \\
\text { those with sight impairment } \\
\text { include involvement of social ser- } \\
\text { vices. Regular follow-up will be } \\
\text { required to monitor progression of } \\
\text { associated anterior segment dys- } \\
\text { genesis and glaucoma with medi- } \\
\text { cal and surgical interventions } \\
\text { where needed. Intraocular surgery } \\
\text { is not advised unless steps are } \\
\text { taken to avoid inflammatory } \\
\text { membrane formation and subse- } \\
\text { quent retinal detachment. Refrac- } \\
\text { tive refraction to reduce/prevent } \\
\text { amblyopia. Genetic counselling } \\
\text { will be offered to the family. }\end{array}$ \\
\hline
\end{tabular}

\subsection{Predictive Setting: the tested person is clinically unaffected but carries an increased risk based on family history}

(To be answered if in 1.9 "B" was marked)

\subsubsection{Will the result of a genetic test influence lifestyle and prevention?}

If the test result is positive (please describe) CPAK is a congenital eye abnormality, therefore if it is not present at birth, it will not develop later in life. Identification of an unaffected carrier will inform family planning.

If the test result is negative (please describe). The result will inform family planning.

3.2.2 Which options in view of lifestyle and prevention does a person at-risk have if no genetic test has been done (please describe)?

Vision can vary depending on severity of associated ocular anomalies. It can affect schooling and limit professions which require perfect vision. Hence, a clinically confirmed diagnosis can help in providing guidance regarding career choice. 
3.3 Genetic risk assessment in family members of a diseased person

(To be answered if in 1.9 "C" was marked)

3.3.1 Does the result of a genetic test resolve the genetic situation in that family?

Yes.

3.3.2 Can a genetic test in the index patient save genetic or other tests in family members?

If molecular testing has identified a FOXE3 variant in the index patient, clinical examination can identify and exclude disease in relatives. However, further genetic tests are required to determine the carrier status. It is important to consider that heterozygous variants in FOXE3 can cause associated ocular anomalies, so patients should be examined to exclude any manifestations [4-7].

3.3.3 Does a positive genetic test result in the index patient enable a predictive test in a family member?

Yes.

\subsection{Prenatal diagnosis (To be answered if in 1.9 " $D$ " was marked)}

\subsubsection{Does a positive genetic test result in the index patient enable a prenatal diagnosis?}

Yes, however, it has to be balanced with the severity of the condition. Primary aphakia is usually accompanied by anterior segment dysgenesis, which may prove extremely difficult to manage. Acting upon a positive result in terms of termination is not always advised as some level of treatment can be provided. Transabdominal ultrasound at 23 weeks gestation has detected CPAK [8]. Identification of a causative FOXE3 variant allows for pre-implantation diagnosis.

\section{If applicable, further consequences of testing}

Please assume that the result of a genetic test has no immediate medical consequences. Is there any evidence that a genetic test is nevertheless useful for the patient or his/her relatives? (Please describe)

Genetic testing for FOXE3 variants will provide a molecular diagnosis. This yields information regarding carrier status and provide choices that would not otherwise be available to facilitate decision making for the patient and their family. Genetic testing is essential for defining inheritance patterns, carrier status and enabling effective genetic counselling with consequent implications for prenatal or pre-implantation genetic diagnosis.

Acknowledgements This work was supported by EuroGentest2 (Unit 2: "Genetic testing as part of health care"), a Coordination Action under FP7 (Grant Agreement Number 261469) and the European Society of Human Genetics.

\section{Compliance with ethical standards}

Conflict of interest The authors declare that they have no conflict of interest.

\section{References}

1. Sowden JC. Molecular and developmental mechanisms of anterior segment dysgenesis. Eye. 2007;21:1310-8.

2. Valleix S, Niel F, Nedelec B, Algros M-P, Schwartz C, Delbosc B, et al. Homozygous nonsense mutation in the FOXE3 gene as a cause of congenital primary aphakia in humans. Am J Hum Genet. 2006;79:358-64.

3. Anjum I, Eiberg H, Baig SM, Tommerup N, Hansen L. A mutation in the FOXE3 gene causes congenital primary aphakia in an autosomal recessive consanguineous Pakistani family. Mol Vis. 2010;16:549-55.

4. Semina EV, Brownell I, Mintz-hittner HA, Murray JC, Jamrich M. Mutations in the human forkhead transcription factor FOXE3 associated with anterior segment ocular dysgenesis and cataracts. Hum Mol Genet. 2001;10:231-6.

5. Reis LM, Tyler RC, Schneider A, Bardakjian T, Stoler JM, Melancon SB, et al. FOXE3 plays a significant role in autosomal recessive microphthalmia. Am $\mathrm{J}$ Med Genet Part A. 2010;152A:582-90.

6. Iseri SU, Osborne RJ, Farrall M, Wyatt AW, Mirza G, Nu G, et al. Seeing clearly: the dominant and recessive nature of FOXE3 in eye developmental anomalies human mutation. Hum Mutat. 2009;30:1378-86.

7. Doucette L, Green J, Fernandez B, Johnson GJ, Parfrey P, Young T. A novel, non-stop mutation in FOXE3 causes an autosomal dominant form of variable anterior segment dysgenesis including Peters anomaly. Eur J Hum Genet. 2011;19:293-9. https://doi.org/ 10.1038/ejhg.2010.210.

8. Meglio FD, Vascone C, Meglio LD, Turco LCL, Vitale SG et al. Case report ultrasound prenatal diagnosis of congenital primary aphakia: case report. J Prenat Med. 2015;9:16-7. 